\title{
Feeling and Liking Responses to Television Programs: An Examination of Two Explanations for Media-Context Effects
}

\author{
JOHN P. MURRY, JR. \\ JOHN L. LASTOVICKA \\ SURENDRA N. SINGH*
}

\begin{abstract}
This research empirically examined how the feelings elicited by television programs and the liking of television programs affected viewers' evaluations of commercials. Subjects' feelings were manipulated by viewing a positive, negative, or neutral emotion-eliciting program while program liking was controlled statistically. Viewers' liking of programs positively influenced attitude toward the ad and attitude toward the brand, with the effect on the latter mediated through the former. Feelings elicited by the programs had no effect on these same attitudes. The influence of program liking on attitude toward the ad, and subsequently on attitude toward the brand, was moderated by both commercial involvement and the commercial's position in a sequence of commercials.
\end{abstract}

$\mathrm{R}$ ecent research indicates that television programming surrounding commercials is an important determinant of advertising message success (see, e.g., Schumann and Thorson 1990). Specifically, both program-elicited feeling states ${ }^{1}$ (Goldberg and Gorn 1987; Pavelchak, Antil, and Munch 1988) and liking for the program (Schumann 1986) have been identified as alternative program-context variables. However, because research on these two variables has been conducted independently, the relationship between the two has not been examined. Therefore, it is currently difficult to predict whether a liked program, such as Terms of Endearment, that elicits negative feelings would enhance or diminish the performance of embedded commercials. This research clarifies the distinction between program liking and program-elicited feelings and then empirically examines the potential that each has to influence the performance of embedded television advertising.

The article is structured as follows. First, we review research concerning the influence of program-elicited feelings and program liking on viewers' evaluations of

*John P. Murry, Jr., is assistant professor of marketing, Graduate School of Business, University of Wisconsin, Madison, WI 53706. John L. Lastovicka is professor of business, and Surendra N. Singh is associate professor of business, both at the School of Business, University of Kansas, Lawrence, KS 66045. This research was funded by awards to J.P.M. from the University of Kansas School of Business Research Fund. The authors are grateful for the helpful suggestions provided by Jon Austin, Peter Dacin, Christine Moorman, Mike Rothschild, and Dan Smith. embedded advertising. We then discuss the relationship between program-elicited feeling states and liking for programs. Third, we propose a model in which we view both involvement with the commercial and the ad's relative position in a sequence (or pod) of commercials as moderators of program-context effects. Attitude toward the ad $\left(A_{\mathrm{ad}}\right)$ is predicted to mediate media context effects on attitude toward the brand $\left(A_{\mathrm{br}}\right)$. Finally, this model is empirically tested.

\section{CONCEPTUAL FOUNDATION}

The high correlation traditionally found between feelings and liking led McGuire (1985) to suggest that the constructs are redundant. However, recent research indicates that these reactions to advertising are distinct (Madden, Allen, and Twible 1988) and that each has a unique influence on brand evaluations (Stayman and Aaker 1988). The present study extends this distinction between feelings and liking into the domain of television-program-context effects. Specifically, we propose that programs elicit both feeling states and program-

\footnotetext{
'Researchers disagree concerning the distinction between moods and emotions (Gardner 1985; Isen 1984; Plutchik 1980). Both are considered feeling states, but moods are generally defined as being milder than emotions and are not directed at a particular stimulus. However, television programming can elicit feeling states of varying intensity, and viewers frequently attribute such feelings to the programming. Because it is not possible to separate the effects of these state variables empirically, we do not make a distinction between the two.
} All rights reserved. 0093-5301/92/1804-0003\$2.00 
liking reactions and that these distinct responses need to be studied simultaneously.

\section{Program-elicited Feelings}

Feelings are temporary affective states that are subjectively perceived by an individual. Past research has generally found that the valence of a feeling state colors evaluations in a direction consistent with the feeling state (Gardner 1985; Goldberg and Gorn 1987; Isen 1984). Consumer researchers have provided a number of explanations for how feelings influence advertising evaluations. For example, Lutz, MacKenzie, and Belch (1983) suggest a conditioning paradigm in which attitudes are conditioned by moods. Goldberg and Gorn (1987) offer a mood-congruency/accessibility hypothesis in which moods increase the accessibility of previously stored cognitions that possess a similar valence. As a result, happy or sad programs may bias evaluations by increasing the likelihood that viewers will recall product experiences that have a similar valence.

Although it is clear that experiencing positive feeling states enhances evaluations, the influence of negative feelings is not as well understood. Research suggests that people are motivated to maintain positive feeling states and "repair" negative feeling states (Isen 1984; Zillman 1988). Thus, negative feeling states created by a program may enhance commercial performance if viewers focus their attention on the positive aspects of commercials in the hope of feeling better.

\section{Program Liking}

In contrast to feeling states, program liking is a summary evaluation of the experience of viewing a television program. This is consistent with the argument of Abelson et al. (1982) that summary evaluations should be distinguished from affective responses. Past research indicates that associating a targeted attitude object with a salient context element can lead to the targeted object's evoking a similar attitudinal response. For example, Gorn (1982) found that products associated with liked music were preferred to those paired with disliked music. Similarly, Schumann (1986) suggested that liking for surrounding television programming influences evaluations of advertised brands. He found that placing ads in liked programs resulted in more positive product impressions than placing the same ads in disliked programs. Hence, watching an ad when the program-liking evaluation is salient should influence $A_{\mathrm{ad}}$ and $A_{\mathrm{br}}$ in a direction consistent with program-liking valence.

\section{Program-elicited Feelings and Program Liking}

There are several reasons for distinguishing between program-elicited feelings and program liking in mediacontext research. First, outside of academic laboratories, consumers are unlikely to view programming they do not like. Thus, if researchers incorrectly assume that the elicitation of negative feelings necessarily leads to an undesirable viewing experience, then program-context research will be myopically limited to the study of programs that elicit positive feelings. Second, if programs elicit both feeling and liking responses, then these two variables can become confounded, making it difficult to clearly attribute causality. Third, when the valence associated with program liking and feeling states are opposite, theories concerning the role of program liking and program-elicited feelings make contrary predictions concerning the impact of programming on embedded advertising. Hence, if an advertising manager needed to decide on purchasing ad time in a liked dramatic program that elicited negative feelings, one approach advises making the purchase while the other does not.

A theoretical explanation is needed for the roles that both program-elicited feelings and program liking play in influencing viewers' attitudes toward ads and brands. By definition, viewers enjoy watching programs that elicit positive feelings. Consequently, theories concerning program-elicited feelings and program liking make similar predictions for programming's influence on advertising placed in liked programming that elicits positive feelings. In contrast, when the valence associated with program-elicited feelings and program liking do not correspond, it becomes important to understand which response is likely to have the greatest influence on evaluations of embedded advertising. To this end, it is useful to consider why programs that evoke negative feelings that are normally considered unpleasant are frequently well liked.

The popularity of programs eliciting negative feelings suggests that viewers respond differently to the negative feelings evoked by dramatic television programming compared with negative feelings elicited by real-life events. If viewers of a news program attribute negative feelings to events that have serious consequences for themselves, then it follows that they would not enjoy the television-viewing experience. However, viewers of dramatic programs are aware that the program is simply "art" imitating life and not real life. Therefore, consumers attribute their feelings to the creative skills of actors and writers rather than to any real-life events. In the arts this process of empathizing with a dramatic program is characterized as a "willing suspension of disbelief" (Coleridge 1975). Readers or viewers willingly suspend their disbelief regarding a drama to vicariously experience the art. Indeed, the temporary arousal of feelings, such as anger, sadness, or fear, may help viewers achieve a satisfying level of internal stimulation as long as no real harm has befallen anyone on the stage or screen (Larsen, Diener, and Cropanzano 1987).

This implies that liking of a program is not determined by the elicitation of any specific feeling state per se. Rather, Zillman $(1988$, p. 331$)$ notes that viewers 
FIGURE 1

THE INFLUENCE OF PROGRAM CONTEXT, COMMERCIAL INVOLVEMENT, AND POD POSITION ON $A_{\mathrm{ad}}$ AND $A_{\mathrm{br}}$

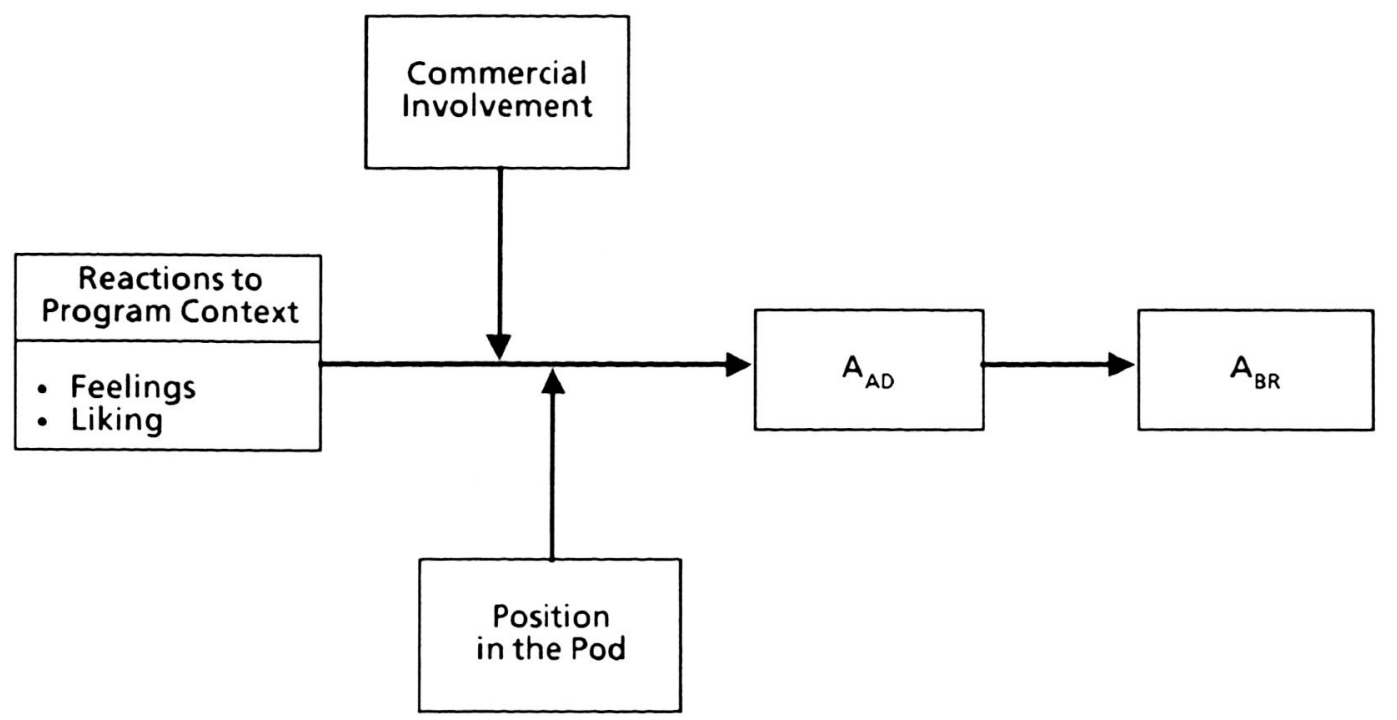

"reject those [programs] that don't 'feel right' and keep on trying until they find something to their liking." At times viewers may like watching a sad movie while at other times their mood needs may direct them to watch a humorous program. The selection of a program, however, is ultimately determined by whether viewers anticipate liking the viewing experience. This "experiential" perspective is consistent with Holbrook and Hirschman's (1982) position that consumption activities include the pursuit of fantasy, feelings, and fun. Hence, feelings are a part of the television-viewing experience while program liking is an evaluation of the pleasure derived from the viewing experience. What makes dramatic programming unique from real-life stimuli, however, is that programs that elicit negative feeling states are frequently well liked.

In summary, feeling and liking responses to programs are distinct. Further, their valences do not necessarily correspond. What remains to be investigated is whether program liking or the valence of the program-evoked feeling state is the more important influence on embedded advertising.

\section{THE MODEL}

Figure 1 portrays our model, which indicates that program-elicited feelings and program liking are expected to influence advertising evaluations. Specifically, in the model, (1) commercial involvement and pod position are hypothesized to moderate the impact of program context on $A_{\text {ad }}$ and $A_{\mathrm{br}}$, and (2) $A_{\text {ad }}$ is posited to mediate programming's influence on $A_{\mathrm{br}}$. The following discussion outlines the model's predictions.

\section{The Moderating Effects of Commercial Involvement and Pod Position}

Commercial Involvement. Prior research reveals that, when nonrelevant messages are processed in a loweffort fashion, factors peripheral to a brand's benefits (i.e., spokesperson likability) exert an important influence on brand evaluations (Greenwald and Leavitt 1984; Petty, Cacioppo, and Schumann 1983). Schumann (1986) extended this low-involvement perspective to program-context research by hypothesizing that, when a message is not considered relevant, the message will not be closely evaluated and program liking will serve as a peripheral cue in the formation of brand impressions. Although he found that program liking influenced brand evaluations, its impact was strongest in higher involvement.

Schumann's (1986) results may be due to liked programs' also eliciting more positive feeling states. The elaboration-likelihood model (ELM) specifies that feelings play different roles depending on the level of processing involvement. Feelings should serve as a simple cue when processing involvement is low and may influence the extent of processing when involvement is moderate. When processing involvement is high, feelings can serve as a central argument or they may bias arguments. Indeed, Schumann (1986) found that viewers in the more involving processing condition evoked more positive thoughts about the product when they watched programs that made them feel good.

In contrast to feelings, there is little theoretical justification for predicting that program liking influences $A_{\text {ad }}$ and $A_{\text {br }}$ when these attitudes are formed under more involved processing. Program liking is an evaluation of 
a specific viewing experience rather than a pervasive feeling state. Therefore, it would be less likely to prompt the elicitation of product-related thoughts or to be construed as a relevant argument for evaluating product quality. Accordingly, program liking should be restricted to serving as a peripheral cue that would have its greatest influence on the evaluations of less involving commercials.

Position of Commercials in the Pod. It is simplistic to focus strictly on the effect that program context has on an individual commercial when television viewers are usually exposed to pods or sequences of commercials (Park and McClung 1987). In essence, the message pod is a second environment that can change the salience of either program-elicited feeling states or programliking evaluations. Because television commercials separate a target commercial from the programming, it is likely that the salience of feelings and liking toward the program will diminish over the course of a typical commercial break. As such, programming should have less influence on those commercials located at the end of the pod.

\section{The Mediating Effect of $A_{\text {ad }}$}

Much research has shown that $A_{\text {ad }}$ mediates many advertising effects on consumers' subsequent brand attitudes (Mitchell and Olson 1981). This ongoing interest in the $A_{\text {ad }}$ construct is due to the empirical evidence that many non-brand-related factors ultimately influence $A_{\mathrm{br}}$ through their impact on $A_{\mathrm{ad}}$. For example, recent studies indicate that $A_{\text {ad }}$ mediates the influence that both ad-generated feelings and consumers' attitudes toward advertisers have on $A_{\mathrm{br}}$ (Burke and Edell 1989; MacKenzie and Lutz 1989). These studies suggest that $A_{\text {ad }}$ is a summary construct that is capable of integrating several areas of advertising research. In fact, MacKenzie and Lutz (1989) propose that program context is an antecedent of $A_{\text {ad }}$ and that $A_{\text {ad }}$ would mediate programcontext influences on $A_{\mathrm{br}}$. This proposition has not been empirically tested.

\section{SUMMARY OF RESEARCH ISSUES}

The principal concern of this research is to explicate the relative influence of both feeling and program-liking responses on viewers' evaluations of advertising. This issue remains an important topic to investigate because previous advertising research has not simultaneously examined the impact of these two distinct responses to programming. The second goal is to begin to unravel the conditions and the processes by which viewers' reactions to programming influence $A_{\mathrm{ad}}$ and $A_{\mathrm{br}}$.

To these ends, an experiment was conducted to determine (1) the relative influence that both programelicited feelings and program liking have on viewers' $A_{\text {ad }}$ and $A_{\mathrm{br}},(2)$ the potential for commercial involvement and pod position to moderate the impact of pro- gram-elicited feelings and liking responses on viewers' $A_{\text {ad }}$ and $A_{\text {br }}$, and (3) whether $A_{\text {ad }}$ mediates programming's influence on $A_{\mathrm{br}}$.

\section{METHOD}

\section{Stimuli Selection}

A total of six programs (two positive, two negative, and two neutral programs) and six commercials (three more involving and three less involving) were selected through a series of pretests. Administering manipulation checks in the main experiment would have confounded the program and commercial-involvement manipulations. Therefore, the following pretests served as proxies for manipulation checks in the main experiment.

Selection of Programs. The three key criteria for selecting programs were that they (1) elicited the required feeling responses from viewers, (2) were viable viewing options for the subject population, and (3) were at least somewhat appealing to watch. After an initial search, six programs meeting these criteria were found and professionally edited into brief videos. ${ }^{2}$ Feelings elicited by the six programs were then examined in a split-plot single-factor design. Twenty-five undergraduates each viewed three programs that elicited positive, negative, and neutral feelings, respectively. Subjects viewed one program in each session, with each session scheduled three days apart. Plutchik's (1980) eight emotion dimensions were assessed using a 64-adjective scale that was administered at the point in the program at which the experimental pod would be inserted in the main experiment. As Table 1 indicates, relative to the neutral programming, the negative programming elicited significantly higher levels of fear, surprise, sadness, disgust, and anger, whereas the positive programs elicited higher levels of anticipation, joy, and acceptance. The feelings elicited by the neutral programs fell consistently between those elicited by the positive and negative programs.

Selection of Commercials. The four most involving and six least involving ads were initially selected from an "armchair" review of over 200 regional commercials contained on producers' demonstration tapes. None of these ads had been aired in the study's area. These 30second ads were then evaluated by 41 undergraduate student subjects who individually viewed two of the 10 "candidate" commercials. The order of presentation was counterbalanced. After watching each commercial,

\footnotetext{
${ }^{2}$ The six programs were "The Cosby Show," "Cheers," "The Day After," Brian's Song, Words of Heart, and "The Iron Curtain Rises." The first two were positive, the next two were negative, and the last two were neutral emotional programs. As noted in Design and Analysis Limitations, the negative programming required additional time to elicit the desired feelings. However, since no programming followed the experimental pod of commercials, the time between subjects' exposure to the commercials and their completion of the dependent measures was constant across all treatments.
} 
TABLE 1

EMOTIONAL PROFILES FROM PROGRAM PRETESTS

\begin{tabular}{lcccc}
\hline \hline & \multicolumn{4}{c}{ Means } \\
\cline { 2 - 4 } $\begin{array}{c}\text { Emotive } \\
\text { dimensions }\end{array}$ & $\begin{array}{c}\text { Negative } \\
\text { emotional } \\
\text { programs }^{\mathrm{a}}\end{array}$ & $\begin{array}{c}\text { Positive } \\
\text { emotional } \\
\text { programs }^{\mathrm{b}}\end{array}$ & $\begin{array}{c}\text { Neutral } \\
\text { emotional } \\
\text { programs }^{\mathrm{c}}\end{array}$ & $\begin{array}{c}\text { Cronbach } \\
\alpha\end{array}$ \\
\hline Fear & $21.4^{\mathrm{d}}$ & $12.2^{\mathrm{d}}$ & 14.9 & .82 \\
Surprise & $20.2^{\mathrm{d}}$ & 15.6 & 18.0 & .80 \\
Sadness & $25.7^{\mathrm{d}}$ & $10.2^{\mathrm{d}}$ & 14.4 & .95 \\
Disgust & $17.8^{\mathrm{d}}$ & 11.8 & 14.4 & .78 \\
Anger & $16.8^{\mathrm{d}}$ & 12.4 & 13.0 & .84 \\
Anticipation & 18.7 & $21.9^{\mathrm{d}}$ & 18.1 & .77 \\
Joy & $14.5^{\mathrm{d}}$ & $24.9^{\mathrm{d}}$ & 18.5 & .90 \\
Acceptance & $18.7^{\mathrm{d}}$ & $24.9^{\mathrm{e}}$ & 22.5 & .82 \\
\hline
\end{tabular}

NOTE. - Each emotive dimension was measured with eight scaled adjectives Higher values indicate stronger feelings.

${ }^{a}$ Average program length was 35.5 minutes.

${ }^{\circ}$ Average program length was 17.0 minutes.

${ }^{\mathrm{c} A v e r a g e ~ p r o g r a m ~ l e n g t h ~ w a s ~} 17.5$ minutes.

${ }^{\circ}$ Different from the neutral program at $p<.01$

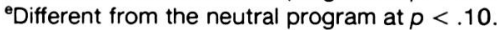

commercial involvement was measured in three ways: (1) message-relevant cognitive responses, (2) the Zaichkowsky personal-relevance inventory (Zaichkowsky 1985), and (3) Thayer's (1978) activation/deactivation measure. Items in the Zaichkowsky scale are meant to measure subjects' product involvement, whereas the Thayer measure indicated activation or arousal state. Use of the Thayer scale follows from suggestions that involvement should be interpreted as a focused state of activation or arousal (Cohen 1983).

The Zaichkowsky and Thayer scales demonstrated acceptable internal consistency, with Cronbach alphas of 0.96 and 0.85 , respectively. The three commercials judged most involving and the three judged least involving were selected to operationalize the involvement manipulation. The more involving set consisted of ads for fast food, a hair gel, and an electric razor, and the less involving set contained ads for macaroni, poultry, and vegetables. The more involving set of commercials generated an average of 3.1 message-relevant thoughts whereas the less involving set elicited only 1.4 thoughts $(t(72)=4.08, p<.01)$. The more involving group was also more arousing, with a mean of 27.6 compared with 19.6 for the less involving set $(t(72)=5.03, p<.01)$. Finally, the more involving set was considered more personally relevant, with a mean of 80.6 compared with 70.5 for less involving ads $(t(72)=2.51, p<.01)$.

\section{Main Experiment}

Design. The hypotheses required an experimental design controlling for program-elicited feelings, program liking, commercial involvement, and commercial position in the pod. Therefore, a multifactor study was implemented in which program-elicited feelings (pos- itive, negative, and neutral), the level of involvement for commercials in the first position in the pod (more and less involving), and the level of involvement for commercials in the fifth position in the pod (more and less involving) were all experimentally manipulated. Program liking was a measured variable that was controlled statistically.

Subjects were randomly assigned to one of three types of program environments and one of two sequences of commercials. In one commercial sequence, the more involving commercial was in the first position in the pod and the less involving commercial was in the fifth position. The other sequence reversed these positions. The design was balanced by rotating the six treatment commercials (three more involving and three less involving) into each position an equal number of times. Three other less involving commercials that were identified in the pretests occupied the middle positions and were held constant across all treatments.

Because each subject viewed a more and a less involving commercial that was in either the first or fifth pod position, this design did not allow us to examine the simultaneous or interactive effects of pod position and commercial involvement. Because our research did not require assessment of such effects, there was no need to use a more conventional, but less efficient, fully crossed and fully nested factorial design.

Subjects. Two-hundred three undergraduate psychology students were recruited and randomly assigned to treatments.

Procedure. Subjects were told that the purpose of the study was to evaluate viewers' impressions of stereo versus conventional monaural television programming. They then watched a program in which the experimental pod was edited into the end of the video. Immediately after subjects had viewed the last commercial, the video recorder was turned off and subjects completed a series of questions concerning the programming. Subjects were then asked to read and think about 60 neutral statements (Velten 1967) that appeared sequentially on the television screen. Typical neutral statements were "The mansion was rented by the delegation" or "Utah is the beehive state." The purpose of this procedure was to equalize subjects' feeling states across program treatments before they completed the dependent measures. The present study's focus was on how viewers form evaluations while watching the ads. Therefore, it was necessary to equalize subjects' feeling states across program treatments before they completed the dependent measures. This procedure isolated the programming's effect on evaluations formed while viewing the ads from any differential effect that might be attributed to subjects' experiencing different feeling states while completing the dependent measures.

Finally, standard measures of commercial effectiveness (described below) were administered. Subjects were 
TABLE 2

HIERARCHICAL REGRESSION MODELS

\begin{tabular}{|c|c|c|c|c|c|}
\hline & \multirow[b]{2}{*}{ Order of variable entry } & \multicolumn{2}{|c|}{$A_{\mathrm{ad}}$} & \multicolumn{2}{|c|}{$A_{\mathrm{br}}$} \\
\hline & & $R^{2}$ & $\Delta R^{2 \mathrm{a}}$ & $R^{2}$ & $\Delta R^{2 \mathrm{a}}$ \\
\hline \multirow[t]{8}{*}{ A. } & $\begin{array}{l}\text { Models for ads in the first } \\
\text { pod position: } \\
\text { 1. Program-involvement } \\
\text { covariate }\end{array}$ & $.03^{*}$ & & & \\
\hline & 2. Program-elicited feelings & .04 & .01 & .01 & \\
\hline & 3. Program liking & .07 & $.03^{*}$ & .03 & $.03^{*}$ \\
\hline & 4. Commercial involvement & .13 & $.05^{\star \star}$ & .04 & .00 \\
\hline & interactions & .14 & .01 & . & $\cdots$ \\
\hline & 6. Program-elicited feelings & & & & \\
\hline & $\begin{array}{l}\text { involvement } \\
\text { 7. Program liking }\end{array}$ & .14 & .00 & .04 & .00 \\
\hline & $\begin{array}{l}\times \text { commercial } \\
\text { involvement }\end{array}$ & .15 & $.01^{+}$ & .06 & $.02^{+}$ \\
\hline \multirow[t]{4}{*}{ B. } & $\begin{array}{l}\text { Models for more involving } \\
\text { ads in the first and fifth } \\
\text { pod positions: }\end{array}$ & & & & \\
\hline & 1. Program liking & .01 & & $.02^{*}$ & \\
\hline & 2. Position in the pod & .02 & .01 & .03 & .00 \\
\hline & $\begin{array}{l}\text { 3. Program liking } \times \text { pod } \\
\text { position }\end{array}$ & .07 & $.04^{\star \star}$ & .08 & $.02^{+}$ \\
\hline
\end{tabular}

${ }^{a} \Delta R^{2}$ refers to the incremental increase in variance explained by each modeled variable.

$+p<.10$

$" p<.05$

$* p<.01$.

then questioned about potential demand artifacts and debriefed about the true purpose of the study.

Measures. The measure booklet contained six items assessing viewers' liking of the programming ${ }^{3}$ (Cronbach $\alpha=0.89$ ), two indicants for each of Plutchik's (1980) eight emotion dimensions, free recall and recognition learning tasks for the products, five items assessing $A_{\text {ad }}$ (Cronbach $\alpha=0.88$ ), and six indicants of $A_{\text {br }}$ (Cronbach $\left.\alpha=0.91\right) .{ }^{4}$ Consistent with Bello, Pitts, and Etzel's (1983) program-context study, program involvement was measured with Thayer's (1978) activation/deactivation checklist (Cronbach $\alpha=0.82$ ).

Design Integrity Checks. One-way analysis of variance (ANOVA) tests across the three program environ-

${ }^{3}$ Program liking was assessed with the following statements: "I'm glad I had a chance to see this program," "I would never watch a rerun of this program on television," "I liked watching this program," "If I knew this program was going to be on television, I would look forward to watching it," "I disliked watching this program more than I do most other TV programs," and "There is something about this program that appeals to me."

${ }^{4}$ The following adjectives assessed $A_{\text {ad: }}$ good/bad, like/dislike, not irritating/irritating, favorable/unfavorable, and boring/interesting Attitude toward the brand was measured with favorable/unfavorable $\mathrm{bad} / \mathrm{good}$, wise/foolish, beneficial/harmful, likable/unlikable, and pleasant/unpleasant. ments for each of the eight emotion dimensions, as well as a multivariate analysis of variance (MANOVA) for all eight measures, indicated that the Velten procedure successfully equalized the subjects' feeling states before they completed the dependent measures (Wilks's $\lambda$ $=8.26$, approximate $F(32,364)=1.84, p>.10)$.

Because of the delayed administration of the commercial measures, no direct measure of commercialprocessing involvement was possible. However, learning was used as an indirect measure because increased involvement should lead to stronger memory traces. Indeed, differences were found in the free-recall task such that products in the more involving set of commercials were better recalled than products in the less involving set $(0.45$ vs. 0.33 , respectively; $F(1,191)=7.91, p$ $<.01)$.

\section{RESULTS}

The discussion of results proceeds in three stages. First, we examine the potential for commercial involvement to moderate the impact of both programgenerated feelings and program liking on $A_{\mathrm{ad}}$ and $A_{\mathrm{br}}$ for ads in the first position of the pod. Second, we examine how an ad's being first or last in the commercial pod affects these programming influences. Finally, we test the potential for $A_{\text {ad }}$ to mediate program context's influence on $A_{\mathrm{br}}$.

We used hierarchical regression to examine the relationships discussed above (Pedhazur 1982). This procedure sequentially introduces covariates and independent variables into a regression model such that each new variable is regressed on the residual variance that is not accounted for by previously modeled variables. An $F$-test is then used to assess the significance level of the incremental variance that is accounted for by each new variable.

\section{Program Liking, Program Feelings, and Commercial-Involvement Moderation}

Separate regression models were used to explain variance in $A_{\mathrm{ad}}$ and $A_{\mathrm{br}}$ for ads in the first position in the commercial pod. The models were sequentially constructed by introducing variables in the following order: (1) program-involvement covariate, (2) programelicited feelings, (3) program liking, (4) commercial involvement, (5) program-involvement interactions, (6) the interaction between program-elicited feelings and commercial involvement, and (7) the interaction between program liking and commercial involvement. Hence, the influence of program liking was assessed only after accounting for the effect of program involvement and program-elicited feelings on $A_{\mathrm{ad}}$ and $A_{\mathrm{br}}$. This ordering provides a conservative test of program liking's influence because any correlation with program involvement or feelings would decrease the likelihood of detecting program-liking effects. These models are reported in part $\mathrm{A}$ of Table 2. 
Schumann and Thorson (1990) posit that program involvement can influence ad performance; thus, program involvement was modeled as a covariate. As part A of Table 2 shows, program involvement did account for a significant amount of variance in the $A_{\text {ad }}$ measure $\left(R^{2}=0.03, F(1,201)=6.26, p<.05\right)$ but was not related to $A_{\mathrm{br}}\left(R^{2}=0.00, F(1,201)=0.32, p>.10\right)$. Consequently, program involvement was excluded from the $A_{\text {br }}$ analyses.

The relative influence of program-elicited feelings and program liking was examined by assessing the incremental variance accounted for by each variable. Program-elicited feelings did not have a significant incremental impact on $A_{\text {ad }}\left(\Delta R^{2}=0.01, F(3,199)=1.35, p\right.$ $>.10)$ or $A_{\mathrm{br}}\left(\Delta R^{2}=0.01, F(2,200)=.91, p>.10\right)$. An inspection of the means indicates that the $A_{\text {ad }}$ scores were lower with neutral programming $(\bar{X}=15.2)$ than with either negative $(\bar{X}=17.0)$ or positive $(\bar{X}=15.8)$ programs. Similarly, $A_{\mathrm{br}}$ was lower with neutral programming $(\bar{X}=18.4)$ than with either negative $(\bar{X}$ $=19.2)$ or positive $(\bar{X}=19.6)$ programs. This pattern is generally consistent with viewers' evaluations of program liking across the different emotional program contexts. In fact, program liking was similar across the positive and negative program environments $(\bar{X}=34.1$ and 31.9 , respectively; $t(200)=1.77, p<.10$ ), whereas the neutral programming environment $(\bar{X}=22.8)$ was much less well liked than either the positive $(t(200)$ $=8.93, p<.01)$ or the negative programming environment $(t(200)=7.23, p<.01)$.

Program liking was then introduced as a two-level categorical variable (well-liked programs and less well liked programs) on the basis of a median split (median $=30$, range $=7-42$ ). Program liking accounted for a significant amount of variance in $A_{\text {ad }}\left(\Delta R^{2}=0.03\right.$, $F(4,198)=6.07, p<.05)$ and $A_{\mathrm{br}}\left(\Delta R^{2}=0.03, F(4,199)\right.$ $=5.34, p<.05)$. As Table 3 reveals, placing ads in wellliked programs enhanced both $A_{\text {ad }}$ and $A_{\text {br }}$ for those ads in the first position of the pod. These results indicate, therefore, that program liking explains more of the variance in $A_{\text {ad }}$ and $A_{\text {br }}$ than do program-elicited feelings. Moreover, commercials placed in well-liked programs were evaluated better than those placed in less well liked programs.

There were no significant differences in $A_{\mathrm{br}}$ between the more and less involving sets of commercials $(\bar{X}$ $=19.0$ and 19.1 , respectively). However, $A_{\text {ad }}$ was significantly better for the more involving set of commercials than for the less involving set $(\bar{X}=17.0$ and 15.0 , respectively; $\Delta R^{2}=0.05, F(5,197)=12.2, p<.01$ ). This is not surprising because viewers are naturally more inclined to direct cognitive resources toward processing those ads that they like better. This finding will be discussed in more detail in Design and Analysis Limitations.

Using program involvement as a covariate for the $A_{\text {ad }}$ model assumes no covariate $\times$ independent variable interaction effects on $A_{\text {ad }}$. This assumption was
TABLE 3

MEAN $A_{\mathrm{ad}}$ AND $A_{\mathrm{br}}$ EVALUATIONS ACROSS PROGRAM TREATMENTS AND POD POSITIONS

\begin{tabular}{|c|c|c|c|c|}
\hline \multirow[b]{2}{*}{$\begin{array}{l}\text { Measure and } \\
\text { program treatment }\end{array}$} & \multicolumn{2}{|c|}{$\begin{array}{l}\text { More involving set } \\
\text { of commercials }\end{array}$} & \multicolumn{2}{|c|}{$\begin{array}{l}\text { Less involving set } \\
\text { of commercials }\end{array}$} \\
\hline & $\begin{array}{c}\text { First } \\
\text { position }\end{array}$ & $\begin{array}{l}\text { Fifth } \\
\text { position }\end{array}$ & $\begin{array}{c}\text { First } \\
\text { position }\end{array}$ & $\begin{array}{c}\text { Fifth } \\
\text { position }\end{array}$ \\
\hline \multicolumn{5}{|l|}{$A_{\mathrm{ad}}:$} \\
\hline Well liked & 18.5 & 17.6 & 15.5 & 14.6 \\
\hline Less well liked & 15.5 & 18.7 & 14.3 & 14.1 \\
\hline \multicolumn{5}{|l|}{$A_{\mathrm{br}}:$} \\
\hline Well liked & 20.6 & 19.6 & 19.4 & 19.4 \\
\hline Less well liked & 17.7 & 19.6 & 18.6 & 17.8 \\
\hline
\end{tabular}

NOTE.-Higher values indicate more positive attitude.

tested and satisfied $\left(\Delta R^{2}=0.01, F(9,193)=0.68, p\right.$ $>.10$ ).

Program-elicited feelings did not interact with commercial involvement to influence either $A_{\text {ad }}\left(\Delta R^{2}\right.$ $=0.00, F(11,191)=0.49, p>.10)$ or $A_{\mathrm{br}}\left(\Delta R^{2}=0.00\right.$, $F(6,196)=0.33, p>.10)$. However, program liking and commercial involvement did interact to influence both $A_{\text {ad }}\left(\Delta R^{2}=0.01, F(12,190)=2.76, p<.10\right)$ and $A_{\mathrm{br}}\left(\Delta R^{2}=0.02, F(7,195)=3.52, p<.10\right)$. Pedhazur (1982, p. 440) recommends using a criterion as high as $p<.25$ for evaluating interaction terms to minimize the type II error probability. Indeed, $A_{\text {ad }}$ for the more involving set of ads was enhanced by being in well-liked programs relative to being in less well liked programs $(\bar{X}=18.5$ vs. $15.5, F(4,98)=7.80, p<.01)$. Program liking did not affect $A_{\text {ad }}$ for the less involving set of commercials $(\bar{X}=15.5$ vs. $14.3 ; F(4,95)=0.70, p$ $>$.10). Similarly, $A_{\mathrm{br}}$ was more strongly influenced for the more involving set of commercials ( $\bar{X}=20.6$ vs. $17.7, F(3,99)=6.27, p<.01)$ than for the less involving set of commercials $(\bar{X}=19.4$ vs. $18.6, F(3,96)=0.11$, $p>.10$ ). These results suggest that program liking had a stronger effect on $A_{\mathrm{ad}}$ and $A_{\mathrm{br}}$ for the more involving commercials.

\section{Program Liking, Commercial Involvement, and Pod-Position Moderation}

As described, the research design balanced the presentation of commercials in the first and last positions of the pod so that any diminishing effect from the programming on evaluations could be examined over pod positions. However, since program-elicited feelings did not influence $A_{\mathrm{ad}}$ or $A_{\mathrm{br}}$ for ads in the first position of the pod, the following analyses will focus on the influence of program liking across both the more and less involving sets of commercials. Regression models were constructed for $A_{\mathrm{ad}}$ and $A_{\mathrm{br}}$ by sequentially introducing (1) program liking, (2) pod position, and (3) the program liking $\times$ pod position interaction term for each set of 
the more involving and less involving commercials. Examination of the interaction terms in these models provides the test for the moderating influence of pod position on program liking's effect. Program involvement was omitted from these analyses because it was not related to $A_{\mathrm{ad}}$ or $A_{\mathrm{br}}$ in either of the models.

As shown in Table 2's part B, program liking interacted with pod position to influence both $A_{\text {ad }}\left(R^{2}=0.04\right.$, $F(3,199)=9.23, p<.01)$ and $A_{\mathrm{br}}\left(R^{2}=0.02, F(3,199)\right.$ $=3.68, p<.10$ ) for the more involving set of ads. Subgroup analyses of the means contained in Table 3 reveal that viewers did not differ in $A_{\text {ad }}(F(1,98)=1.35$, $p>.10)$ or $A_{\mathrm{br}}(F(1,94)=0.31, p>.10)$ for ads in the fifth position across well-liked and less well liked programs. Moreover, neither $A_{\text {ad }}(F(1,104)=0.88, p>.10)$ nor $A_{\mathrm{br}}(F(1,104)=0.69, p>.10)$ differed from the first position to the fifth position in well-liked programming. In contrast, there was a significant enhancement in both $A_{\text {ad }}(F(1,95)=10.39, p<.01)$ and $A_{\text {br }}(F(1,95)=3.16$, $p<.10$ ) from the first to the fifth position in the less well liked programs. These findings suggest that the differences in $A_{\mathrm{ad}}$ and $A_{\mathrm{br}}$ for the first position of the pod are due to a detrimental influence from the less well liked programming rather than to an enhancement effect from the well-liked programming. Furthermore, the negative carryover effect that less well liked programming had on $A_{\text {ad }}$ and $A_{\text {br }}$ dissipated when target ads were placed in the last (fifth) position in the pod.

Consistent with the analyses that focused on ads in the first pod position, program liking did not interact with pod position to influence either $A_{\mathrm{ad}}\left(\Delta R^{2}=0.00\right.$, $F(3,199)=0.45, p>.10)$ or $A_{\text {br }}\left(\Delta R^{2}=0.00, F(3,199)\right.$ $=0.73, p>.10$ ) for the less involving ads. Therefore, pod position only influenced evaluations for the more involving commercials.

\section{Program Liking and $A_{\text {ad }}$ Mediation}

To conclude that $A_{\text {ad }}$ mediates the influence of program liking, two steps of evidence are required: (1) program liking must be significantly related to both $A_{\text {ad }}$ and $A_{\mathrm{br}}$, and (2) the relationship between program liking and $A_{\mathrm{br}}$ should dissipate when $A_{\mathrm{ad}}$ 's effect on $A_{\mathrm{br}}$ is controlled (Baron and Kenny 1986). With respect to the first step, as Table 2's part A reveals, program liking influenced both $A_{\mathrm{ad}}$ and $A_{\mathrm{br}}$. The next step required controlling for the effect of $A_{\mathrm{ad}}$ on $A_{\mathrm{br}}$ by entering $A_{\mathrm{ad}}$ into the regression equation immediately before the program-liking variable. As expected, $A_{\text {ad }}$ did account for a significant amount of variance in $A_{\mathrm{br}}\left(\Delta R^{2}=0.43\right.$, $F(4,198)=152.63, p<.01){ }^{5}$ In addition, controlling for the effect of $A_{\mathrm{ad}}$ on $A_{\mathrm{br}}$ reduced the relationship between program liking and $A_{\mathrm{br}}\left(\Delta R^{2}=0.00, F(5,197)\right.$ $=1.08, p>.10)$. Hence, program liking influenced $A_{\mathrm{br}}$, but this effect is mediated through $A_{\text {ad }}$.

\footnotetext{
${ }^{5}$ Program involvement and program-elicited feelings were previously entered into the model as covariates.
}

\section{Design and Analysis Limitations}

One limitation of this study is that the length of the programs varied across emotional program environments. The six programs varied from a minimum of 17 minutes for "Cheers" and "The Cosby Show" to a maximum of 39 minutes for Brian's Song. Unfortunately, even with professional editing, it was not possible to shorten the longer negative emotional programs and still achieve a strong manipulation. However, there are empirical and conceptual reasons to believe that the longer program length (in and of itself) was not responsible for our results. First, if program length influenced $A_{\mathrm{ad}}$ and $A_{\mathrm{br}}$, then significant differences should be observed across various programs of different lengths. In fact, a series of $t$-tests indicate that there were only four significant differences $(p<.10)$ out of the 30 possible program contrasts for $A_{\mathrm{ad}}$ and $A_{\mathrm{br}}$. Second, introducing the actual minutes of programming as a covariate into the aforementioned models did not change the interpretation of the effects of either program liking or program-elicited feelings. Third, 39 minutes is not a long period of time for watching a television program. As noted earlier, the longer negative programs were nearly as well liked as the shorter positive programs. Therefore, it is unlikely that viewers were either fatigued or irritated by watching longer programs.

A second concern is that $A_{\text {ad }}$ for the more involving set of ads was more favorable than for the less involving set. Hence, one may question whether liking for the ad moderated the program-context effect rather than commercial involvement. Although this potential confound cannot be completely resolved, there is no apparent theoretical reason for why programming would only influence better-liked ads. Further, even though there was no significant difference between subjects' $A_{\mathrm{br}}$ across the more and less involving sets, $A_{\mathrm{br}}$ was still enhanced in the well-liked programming relative to the less well liked program $\left(\Delta R^{2}=0.03, F(3,199)=5.34, p<.05\right)$. If degree of liking for the attitude object rather than involvement was the key moderator, then the program context should have influenced $A_{\mathrm{br}}$ equally for both sets of commercials rather than only influencing $A_{\mathrm{br}}$ in the more involving set.

\section{DISCUSSION}

Our results reaffirm the importance of understanding how media context influences commercial performance. In contrast to Goldberg and Gorn's (1987) conclusions, however, our research shows that program-elicited feelings did not influence viewers' evaluations of embedded commercials. Although feelings undoubtedly influenced viewers' liking of the television programming, our results show that only program liking influenced $A_{\text {ad }}$ and $A_{\text {br }}$. Program liking demonstrated a consistent and predictable effect on $A_{\text {ad }}$ and $A_{\mathrm{br}}$; the size of this effect, however, ranged from moderate to relatively small. 
The influence of program liking did not equally affect all of the embedded commercials. Those commercials processed in a more involving manner and those commercials placed in the first position of the pod were more strongly affected. Finally, the effect of program liking on $A_{\mathrm{br}}$ was mediated through its effect on $A_{\mathrm{ad}}$. Hence, program liking is an antecedent of $A_{\mathrm{ad}}$, but it is $A_{\text {ad }}$ that ultimately influences $A_{\mathrm{br}}$.

These results have clear implications for future research concerning the influence of program context on commercial performance.

\section{Program-elicited Feelings and Program Liking}

This study's findings suggest that advertising managers concerned about the effect of programming on $A_{\text {ad }}$ and $A_{\text {br }}$ should concern themselves with the program-liking variable rather than with the specific feelings that programs elicit. Although feelings may contribute to liking a program, program liking influenced viewers' evaluations of the ads and the brands. This is consistent with Unger and Kernan's (1983) positing that the subjective experience of leisure activities is best represented by measures of intrinsic satisfaction or enjoyment of an experience. Further, they suggest that other dimensions of the leisure experience, such as arousal or fantasy, cause this enjoyment. Similarly, program liking assesses the intrinsic satisfaction that viewers derive from viewing. As such, other dimensions of the television viewing experience, such as arousal, fantasy, and feelings, become subsumed by this overarching liking construct.

Larsen et al. (1987) propose that the activation or deactivation of emotions can help people achieve their "optimal" stimulation level. As such, understimulated individuals may seek out emotionally charged programs to raise their level of stimulation to this optimal level. This reasoning is consistent with the results of our study and implies that viewers may enjoy watching negative emotional programming if that programming evokes a more satisfying level of internal stimulation. As discussed earlier, however, the enjoyment of negative emotional programs likely depends on the type of negative emotional programming (i.e., reality vs. fantasy) that is being watched. The affective experience associated with the arousal of negative emotions that are elicited by a news program dealing with real-life events could have effects opposite to those negative emotions elicited by fantasizing with dramas.

Finally, a series of studies have examined the relationship between $A_{\text {ad }}$ and ad-generated feelings. In many ways, these studies are similar to the present study's concern with program liking and program-elicited feelings. Specifically, $A_{\text {ad }}$ usually refers to an appraisal or liking of the ad while feelings relate to a state that an ad elicits (Madden et al. 1988). Recent studies have investigated both the relative importance of each re- sponse in determining $A_{\mathrm{br}}$ and whether feelings affect $A_{\mathrm{br}}$ independently of their effect on $A_{\text {ad }}$. Although there is evidence that feelings have a moderate direct influence on $A_{\mathrm{br}}$ under low-exposure-frequency conditions (Stayman and Aaker 1988), the more consistent and stronger influence of feelings on $A_{\mathrm{br}}$ occurs through their effect on $A_{\text {ad }}$ (Batra and Ray 1986; Burke and Edell 1989; Holbrook and Batra 1987). Consequently, the results of prior research parallel our findings. Although program-elicited feelings undoubtedly contribute to liking a program, the empirical evidence indicates that program liking is more important than program-elicited feelings. Similar to the $A_{\text {ad }}$ construct, program liking may be a summary construct accounting for the feelings that programs elicit.

\section{Commercial Involvement}

Past research suggests that consumers' use of peripheral cues is most prevalent under low involvement (Petty et al. 1983). However, in apparent contradiction, both our research and Schumann's (1986) report program-context effects under higher involvement. As a start to understanding this conflict, it is useful to recognize that, under conditions of low involvement, consumers may not have formed attitudes about the objects investigated in a given questionnaire (Lastovicka and Bonfield 1982). The issue of when attitudes are formed is aided with Srull's (1984) "on-line" and "off-line" processing paradigm. On-line processing occurs when consumers are motivated to form and store an attitude at the time of message exposure. However, if the message does not relate to current purchasing goals, then the cognitive effort needed to form an attitude is deferred and only information traces are stored. If needed, this information can be recalled later and evaluated to form an attitude off line.

Extending this theory to commercial-involvement research suggests that, when viewers engage in more involved processing of commercials, they are more likely to form ad and brand evaluations on line at the time of exposure. Accordingly, these viewers would develop ad and brand attitudes while the effects of program liking are still salient. Hence, the program-context effect occurs in higher involvement. Conversely, with lower involvement, viewers are less likely to form attitudes at exposure. As a result, they will store only information traces rather than attitudes. Their attitudes would then be derived in reaction to a researcher's questioning at a time when the effect of program liking has dissipated. Thus a program-liking context effect is not found under lower involvement.

This interpretation underscores the importance of Petty et al.'s (1988) suggestion that the impact of context variables should be investigated across a wider range of involvement levels. At a minimum, this should include very low levels common to normal television commercial viewing, moderate levels associated with a minimal 
motivation to process, and the circumstance when consumers actively evaluate commercial messages.

\section{Position in the Pod}

The position-in-the-pod results have important theoretical implications. Previous studies assume that positive program environments enhance evaluations whereas negative programming diminishes evaluations. However, because these studies only compared "positive" with "negative" program contexts, it has not been possible to determine whether their results are due to attitude enhancement from positive programs, or to a diminishing effect from negative programs, or to both. By controlling for pod position, it was possible to examine the relative influence from both positive and negative program environments. No differences in $A_{\mathrm{ad}}$ or $A_{\mathrm{br}}$ were found across pod positions in the well-liked programming, nor across program environments when the commercials were placed in the last position of the pod. Therefore, the significant differences in $A_{\text {ad }}$ and $A_{\mathrm{br}}$ that were observed in the first position of the pod are due to a detrimental effect from less well liked programming rather than to an enhancement effect from well-liked programming.

In general, this finding questions the importance that advertising practitioners currently give to program climates (Goldberg and Gorn 1987). In natural in-home settings, one would expect that most television viewers will watch programs that they like. Hence, viewer selfselection of programming minimizes the negative effects of less well liked programs. To the extent that differences across program environments are only attributable to the detrimental influence of disliked programming, then in natural settings viewer self-selection would minimize any effects from the program environment.

\section{CONCLUSIONS}

The affective experience associated with viewing dramatic television programming appears to be different from the emotional experience usually studied in psychology experiments. As such, consumer researchers should be careful when drawing on these studies for theoretical support. We have demonstrated the uniqueness of television programming as an emoting stimulus by simultaneously controlling for viewers' feeling states and their liking evaluations of the viewing experience. In contrast to previous research, our findings show that program-elicited feelings do not directly influence $A_{\mathrm{ad}}$ and $A_{\mathrm{br}}$. Instead, our results show that program liking exerts an influence that is independent of the specific program-elicited feelings. Future research needs to more fully explicate the relationship between these separate reactions to programming and their subsequent impact on commercials.

[Received April 1989. Revised May 1991.]

\section{REFERENCES}

Abelson, Robert P., Donald R. Kinder, Mark D. Peters, and Susan T. Fiske (1982), "Affective and Semantic Components in Political Perception," Journal of Personality and Social Psychology, 42 (April), 619-630.

Baron, Reuben M. and David A. Kenny (1986), "The Moderator-Mediator Distinction in Social Psychological Research: Conceptual, Strategic, and Statistical Considerations," Journal of Personality and Social Psychology, 51 (6), 1173-1182.

Batra, Rajeev and Michael L. Ray (1986), "Affective Responses Mediating Acceptance of Advertising," Journal of Consumer Research, 13 (September), 234-249.

Bello, Daniel C., Robert E. Pitts, and Michael J. Etzel (1983), "The Communication Effects of Controversial Sexual Content in Television Programs and Commercials," Journal of Advertising, 12 (3), 32-42.

Burke, Marian Chapman and Julie A. Edell (1989), "The Impact of Feelings on Ad-based Affect and Cognition," Journal of Marketing Research, 26 (February), 69-83.

Cohen, Joel B. (1983) "Involvement and You: 1000 Great Ideas," in Advances in Consumer Research, Vol. 10, ed. Richard P. Bagozzi and Alice M. Tybout, Ann Arbor, MI: Association for Consumer Research, 325-328.

Coleridge, Samuel Taylor (1975), Biagraphia Literaria, ed. George Watson, New York: Dutton.

Gardner, Meryl Paula (1985), "Mood States and Consumer Behavior: A Critical Review," Journal of Consumer Research, 12 (December), 281-300.

Goldberg, Marvin E. and Gerald J. Gorn (1987), "Happy and Sad TV Programs: How They Affect Reactions to Commercials," Journal of Consumer Research, 14 (December), 387-403.

Gorn, Gerald (1982), "The Effects of Music in Advertising on Choice Behavior: A Classical Conditioning Approach," Journal of Marketing, 46 (Winter), 94-101.

Greenwald, Anthony G. and Clark Leavitt (1984), "Audience Involvement in Advertising: Four Levels," Journal of Consumer Research, 11 (June), 581-592.

Holbrook, Morris B. and Rajeev Batra (1987), “Assessing the Role of Emotions as Mediators of Consumer Responses to Advertising," Journal of Consumer Research, 14 (December), 404-420.

and Elizabeth C. Hirschman (1982), "The Experiential Aspects of Consumption: Consumer Fantasies, Feelings, and Fun," Journal of Consumer Research, 9 (September), 132-140.

Isen, Alice M. (1984), "Toward Understanding the Role of Affect in Cognition," in Handbook of Social Cognition, Vol. 3, ed. Robert Wyer, Jr., and Thomas Srull, Hillsdale, N.J.: Erlbaum, 179-236.

Larsen, Randy J., Ed Diener, and Russell S. Cropanzano (1987), "Cognitive Operations Associated with Individual Differences in Affect Intensity," Journal of Personality and Social Psychology, 53 (4), 767-774.

Lastovicka, John L. and E. H. Bonfield (1982), "Do Consumers Have Brand Attitudes?" Journal of Economic Psychology, 2 (1), 57-75.

Lutz, Richard J., Scott B. MacKenzie, and George E. Belch (1983), "Attitude toward the Ad as a Mediator of Advertising Effectiveness: Determinants and Consequences," in Advances in Consumer Research, Vol. 10 
ed. Richard P. Bagozzi and Alice M. Tybout, Ann Arbor, MI: Association for Consumer Research, 532-539.

MacKenzie, Scott B. and Richard J. Lutz (1989), "An Empirical Examination of the Structural Antecedents of Attitude toward the Ad in an Advertising Pretest Context," Journal of Marketing, 53 (April), 48-65.

Madden, Thomas J., Chris T. Allen, and Jacquelyn L. Twible (1988), "Attitude toward the Ad: An Assessment of Diverse Measurement Indices under Different Processing 'Sets,'” Journal of Marketing Research, 25 (August), 242-252.

McGuire, William J. (1985), "Attitudes and Attitude Change," in Handbook of Social Psychology, Vol. 2, ed. G. Lindzey and E. Aronson, New York: Random House, 233-346.

Mitchell, Andrew A. and Jerry C. Olson (1981), "Are Product Attributes the Only Mediator of Advertising Effects on Brand Attitude?" Journal of Marketing Research, 18 (August), 318-332.

Park, C. Whan and Gordon W. McClung (1987), "The Impact of Program Contextual Factors on the Effectiveness of TV Commercials," working paper, Graduate School of Business, University of Pittsburgh, Pittsburgh, PA 15260.

Pavelchak, Mark A., John H. Antil, and James M. Munch (1988), "The Super Bowl: An Investigation into the Relationship among Program Context, Emotional Experience, and Ad Recall," Journal of Consumer Research, 15 (December), 360-367.

Pedhazur, Elazar J. (1982), Multiple Regression in Behavioral Research: Explanation and Prediction, New York: Holt, Rinehart \& Winston.

Petty, Richard E., John T. Cacioppo, and David W. Schumann (1983), "Central and Peripheral Routes to Advertising Effectiveness: The Moderating Role of Involvement," Journal of Consumer Research, 10 (September), 135-146.

, John T. Cacioppo, Constantine Sedikides, and Alan J. Strathman (1988), "Affect and Persuasion: A Contem- porary Perspective," American Behavioral Scientist, 31 (January/February), 355-371.

Plutchik, Robert (1980), Emotion: A Psychoevolutionary Synthesis, New York: Harper \& Row.

Schumann, David W. (1986), "Program Impact on Attitude toward TV Commercial," in Proceedings of the Division of Consumer Psychology, ed. Joel G. Saegert, Washington, DC: American Psychological Association, 67-73.

and Esther Thorson (1990), "The Influence of Viewing Context on Commercial Effectiveness: A Selection-Processing Model," Current Issues and Research in Advertising, 12 (1), 1-24.

Srull, Thomas K. (1984), "The Effects of Subjective Affective States on Memory and Judgment," in Advances in Consumer Research, Vol. 11, ed. Thomas Kinnear, Provo, UT: Association for Consumer Research, 530-533.

Stayman, Douglas M. and David A. Aaker (1988), "Are All the Effects of Ad-induced Feelings Mediated by $A_{\mathrm{ad}}$ ?" Journal of Consumer Research, 15 (December), 368-373.

Thayer, Robert E. (1978), "Factor Analytic and Reliability Studies on the Activation-Deactivation Adjective Check List," Psychological Reports, 42 (June), 747-756.

Unger, Lynette S. and Jerome B. Kernan (1983), "On the Meaning of Leisure: An Investigation of Some Determinants of the Subjective Experience," Journal of Consumer Research, 9 (March) 381-392.

Velten, Emmett C., Jr. (1967), "The Induction of Elation and Depression through the Reading of Structured Sets of Mood-Statements," unpublished dissertation, Department of Psychology, University of Southern California, Los Angeles, CA 90089.

Zaichkowsky, Judith Lynne (1985), "Measuring the Involvement Construct," Journal of Consumer Research, 12 (December), 341-352.

Zillman, Dolf (1988), "Mood Management through Communication Choices," American Behavioral Scientist, 31 (January/February), 327-340. 